\title{
EL EXISTENCIALISMO DE SARTRE, ORIGENES Y CONTEXTOS: UNA LeCTURA A PARTIR DE HANNAH ARENDT
}

\author{
[ THE EXISTENCIALISM OF SARTRE, ORIGINS AND CONTEXTS: A READING FROM HANNAH \\ ARENDT ]
}

Gerardo Miguel Nieves-Loja * Universidad Nacional de Chimborazo, Ecuador

\begin{abstract}
RESUMEN: En primer lugar, el objetivo de este artículo es conocer el existencialismo de Sartre en el contexto francés y europeo, su origen, su respuesta a la realidad de la época desde su propia interpretación. Luego, es fundamental analizar el punto de vista de Hannah Arendt con respecto a la filosofía existencialista; su lectura de Sartre es bastante iluminadora debido a que, tanto ella como él, fueron testigos $\mathrm{y}$ víctimas de las dos guerras mundiales, sobre todo, vivieron en carne propia, el uno en Francia y la otra en Alemania, el totalitarismo nacionalsocialista de Hitler que provocó la supresión de las libertades políticas de la época. Sartre y Arendt representan la resistencia intelectual con la finalidad de reconstruir la ciudadanía a partir de la libertad, la espontaneidad y la pluralidad.
\end{abstract}

Palabras Clave: Existencialismo; Resistencia; Sartre; Camus; Arendt
AbSTRACT: First, the objective of this article is to know Sartre's existentialism in the French and European context, its origin, its response to the reality of the time from its own interpretation. Then, it is essential to analyze Hannah Arendt's point of view regarding existentialist philosophy; Her reading of Sartre is quite illuminating because, both she and he, were witnesses and victims of the two world wars, especially, they lived in their own flesh, one in France and the other in Germany, Hitler's National Socialist totalitarianism that caused the suppression of the political liberties of the time. Sartre and Arendt represent intellectual resistance in order to rebuild citizenship based on freedom, spontaneity and plurality.

KeYwords: Existentialism; Resistance; Sartre; Camus; Arendt

\section{INTRODUCCIÓN}

Tean-Paul Charles Aymard Sartre, (1905-1980) es un filósofo, escritor, novelista y dramaturgo francés que fue testigo directo de las dos grandes guerras que afectaron a Europa; sobre todo, vivió en carne propia la llegada del nacionalsocialismo alemán de Hitler. Cabe recordar que la editorial francesa Gallimard fue fundamental para la publicación de los escritos de Sartre; solo cuando los nazis liberaron esta editorial, se pudo publicar L'être et le Néant. En 1939 fue tomado prisionero por los nazis. Después de la guerra, Sartre se comprometió políticamente contra el colonialismo y se acerca a los comunistas de la época. En este contexto, Sartre representa y se constituye en uno de los máximos representantes del existencialismo

* Doctor en Filosofía por la Universidad de Estrasburgo, Francia. Actualmente es docente investigador y Coordinador de la Gestión de Publicaciones y Propiedad Intelectual (GCPI), de la Universidad Nacional de Chimborazo en Ecuador. m@ilto: gnieves@unach.edu.ec / gnievesloja@yahoo.es 
francés ${ }^{1}$ y europeo, movimiento que estudia la condición humana, el significado de la vida, la libertad y la responsabilidad individual. Como veremos más adelante, esta corriente filosófica, el existencialismo, hunde sus raíces en Hegel, Kant y Heidegger y el mismo Sartre fue influenciado por tales pensadores.

Es importante encontrar en la obra de Sartre un compromiso sin vacilación con

128 la clase obrera, con aquellos que estaban siendo víctimas de los totalitarismos de la época, un mundo alienado, con miedo a la libertad sin atreverse a tomar actitudes de rebelión e inconformismo. Sartre llega a reconocer y a tomar una actitud autocritica cuando declara que el mundo europeo, su cultura, que se creía ser el sujeto de la historia, cometió un grave error, al no reconocer los valores de las culturas indígenas y negras (Fanon, 1963). Sin duda alguna, Sartre fue un escritor crítico, cuyo objetivo era llegar a una verdad.

En primer lugar, el objetivo de este artículo es conocer el existencialismo de Sartre en el contexto francés y europeo, su origen, su respuesta a la realidad de la época desde su propia interpretación. Luego, es fundamental analizar el punto de vista de Hannah Arendt (2002) con respecto a la filosofía existencialista; su lectura de Sartre es bastante iluminadora debido a que, tanto ella como él, fueron testigos y víctimas de las dos guerras mundiales, sobre todo, vivieron en carne propia, el uno en Francia y la otra en Alemania, el totalitarismo nacionalsocialista de Hitler que provocó la supresión de las libertades políticas de la época. Sartre y Arendt representan la resistencia intelectual con la finalidad de reconstruir la ciudadanía a partir de la libertad, la espontaneidad y la pluralidad.

En este contexto caben las preguntas: ¿Por qué el existencialismo recibió numerosas acusaciones, y cuáles fueron las respuestas que dio Sartre? ¿Cuál es el origen y el contexto del existencialismo de Sartre? ¿Qué lectura hace Hannah Arendt de la filosofía existencialista de Sartre? ¿Cuáles son los grandes temas del existencialismo de Sartre?

En este trabajo se analizan, primeramente, las respuestas que Sartre dio a las acusaciones que recibiera en su contra. Seguidamente, y tomando como referencia a Hannah Arendt, se estudia el existencialismo en sus orígenes y se relaciona con otros pensadores de la época, principalmente, poniendo énfasis en el existencialismo francés. Finalmente, se trata de presentar el existencialismo de Sartre, que dista mucho del de Heidegger, en cuanto que el hombre es dueño y constructor de su destino histórico.

\section{DE LOS ORÍGENES DE LA(S) FILOSOFÍA(S) DE LA EXISTENCIA.}

Jean Paul Sartre fue acusado, tanto por comunistas y cristianos, por querer quitar los mandamientos de Dios e ir contra de la solidaridad humana, promoviendo, en cambio, un hombre aislado del mundo y refugiado en su soledad. Los acusadores afirman que el existencialismo pone énfasis en lado malo de la vida humana, que es sombrío (Sartre, 1946).

El existencialismo ha sido acusado, también, de considerar al hombre en su subjetividad individual. Según Sartre, lo que se necesita es una doctrina basada en la verdad y no en un conjunto de bellas teorías llenas de esperanza, pero sin fundamento real. Sin embargo, hay quienes consideran que el existencialismo ha dado una importancia grande al problema de la dignidad del hombre; que no le hace objeto, como ocurre con el materialismo, y que trata a los hombres como objetos. El reino de los humanos vela por valores distintos a los del reino material.

De igual manera, el existencialismo ha recibido críticas al ser considerado como 
una doctrina que promueve gente con un espíritu de hacer lo que quiera, de ser anarquistas, de juzgar a los otros. Sin embargo, nadie está impedido de no elegir: yo puedo siempre elegir, incluso si no elijo; he elegido también una actitud y siempre llevo la responsabilidad de la elección, lo cual no es un capricho, es una responsabilidad. Junto a las críticas que recibió el existencialismo, es importante analizar de donde proviene esta corriente de pensamiento, o talvez, es mejor hablar de "existencialismos", sus principales autores y defensores.

Según Hannah Arendt (2002), la filosofía de la existencia tiene una historia centenaria que inicia con Schelling y Kierkegaard y se desarrolla con Nietzsche. Luego, con Bergson se llamará filosofía de la vida, antes de llegar a su fin en Alemania con Scheler, Heidegger y Jaspers.

El termino existencia no designa más que ser del hombre, el cual es reemplazado por existencia. Después, es Husserl quien reconstruye la relación entre ser y pensamiento a partir de la conciencia; una verdadera refundación en el mundo de la fenomenología que pone el acento en las petites choses, pequeñas cosas que esconden el misterio de la realidad, donde el hombre es creador del mundo y de sí mismo. Según Kant, el hombre adquiere conciencia de su independencia, de su libertad, siendo capaz de determinar sus actos sobre la base de la buena voluntad. Los conceptos fundamentales de Kant son la libertad y la dignidad humanas (Ferry, 2006).

En esta misma línea, es el pensador alemán Karl Jaspers, muy amigo de Hannah Arendt, quien rompe con la filosofía tradicional en su obra Psychologie des conceptions $d u$ monde (1919), relativizando todos los sistemas filosóficos, presentándolos como construcciones mitologizantes, en las cuales el hombre busca refugio para escapar de las verdaderas preguntas de su existencia, las que son respondidas mediante un método pedagógico muy parecido al de Sócrates, llamado l'appel. Aquí, el filósofo no lleva una vida distinta a sus semejantes, al contrario, él puede llamar a los otros y viceversa. Se trata de filosofar con los otros. Este pensamiento de Jaspers es muy cercano a la posición de Arendt, para quien Sócrates representa la filosofía más pura de Occidente en el sentido de que recupera la pluralidad, el diálogo abierto con los ciudadanos de la ciudad (polis). De manera que el término existencialismo, por la primera vez, se debe a Jaspers, quien emplea en una carta que dirige a Jean Wahl en 1937. A esto se suma el itinerario intelectual de Arendt, quien lleva a cabo sus estudios en un ambiente totalmente impregnado de filosofía de la existencia; a sus 15 años de edad lee a Jaspers y luego se interesa por la filosofía de Kierkegaard, tres años después viaja a Marbourg para estudiar teología, era la época de Heidegger, quien comenzaba a ser muy reconocido en los medios universitarios. Posteriormente, Arendt viaja a Fribourg para seguir el curso con Husserl, de quien es heredero también Sartre, para finalmente llegar a Heidelberg, donde hará su tesis doctoral con Karl Jaspers. Por lo tanto, Arendt estudia en un ambiente donde la filosofía de la existencia estaba vigente (2006); y se puede constatar también como ella, su pensamiento, se encontraba más cercana a Jaspers que a su maestro Heidegger, el cual no tenía otro futuro que la negación de si, mientras que Jaspers daba respuestas al mundo contemporáneo.

Este ambiente existencialista estaba animado por ideas "revolucionarias". Los filósofos estaban poco inclinados a favor de la contemplación metafísica, más bien habían optado por una actitud crítica frente a las formas tradicionales de la vida. Jaspers, en 1935 afirmaba que la voluntad de comunicación es universal y procede de dos fuentes: la existencia y la razón, estas son lo que se conoce como esencia del hombre, y no pueden ser aprehendidas por el pensamiento. De esta manera Arendt, veinte años más tarde, abandonará el universo griego al cual le condujo Heidegger, y tomará el rumbo de sus propios trabajos en el terreno de la historia política y cultural, 
lógicamente en correspondencia permanente con su maestro Jaspers.

Para Jaspers, la existencia no es una forma del ser, sino una forma de la libertad del hombre, donde "el (hombre) se opone, como posibilidad de su espontaneidad, contra el simple hecho de ser un resultado" (1919, p. 134). El hombre es posible de existencia en el ser ahí, el cual se encuentra orientado por su libertad y, fundado en la espontaneidad, hacia la comunidad. El ser no es conocible y no puede ser experimentado. Se puede constatar que el existencialismo establece unos temas muy definidos: la libertad, la espontaneidad, conceptos, éstos, muy importantes en la teoría política de Arendt, con los cuales defiende al ciudadano aislado y silenciado frente a los poderes totalitarios. Es justamente la época cuando se profundiza la reflexión en Francia, época en la cual la situación política estaba siendo bastante complicada por la ocupación de las tropas de Hitler en territorio francés. El existencialismo es una reflexión que pone en relevancia la condición humana que había sido completamente olvidada en los campos de concentración, como también el significado de la vida que nunca puede ser un medio, y, finalmente, el aspecto de la libertad que había desparecido con el advenimiento de lo social del hombre moderno en detrimento de una política participativa y plural que favoreciera a los individuos a participar en el ámbito de lo público. De ahí la importancia de profundizar en el existencialismo francés.

\section{EL EXISTENCIALISMO FRANCÉS.}

El 14 de junio de 1940, el nazismo alemán se toma Paris; se cambia la bandera tricolor francesa -azul, blanco, rojo- por la esvástica, el símbolo del nacionalsocialismo de Hitler, quien llegó a esta ciudad cuatro días después de ser ocupada. Sin embargo, aparece un grupo de resistencia en Paris, entre los cuales se encontraba un grupo de intelectuales que no aceptaba someterse, entre otras cosas, a las reglas de la sociedad moderna. Llama mucho la atención, cómo las élites revolucionarias no dijeron absolutamente nada. Igual situación se presentó en quienes conformaban los grupos de izquierda. En esa época, La filosofía se encontraba enraizada en el individuo, no así el movimiento llamado existencialismo que provenía de Francia. Entre los principales representantes del existencialismo se encuentran Sartre y Albert Camus. Sin embargo, el existencialismo provocó tantos malentendidos, que el mismo Camus llega a declarar que él no es un existencialista.

Hannah Arendt se encuentra en Paris en abril de 1952, es cuando escribe a Camus una postal con el siguiente mensaje: "Je suis à Paris pour quelque semaines et j'aimerais vous voir, si cela peut s'arranger sans vous importuner. J'ai lu L'Homme révolté que j'aime beaucoup, à vrai dire c'est la seule raison de cette note " (Baudoui, 2017, p. 3) ${ }^{2}$ Y, el esposo de Arendt Heinrich Blücher afirma también «sans aucun doute pour le moment le meilleur homme en France. Tous les autres intellectuels sont tout juste supportables (...) voilà un authentique philosophe moderne " (Arendt, 1996, p. 46) ${ }^{3}$ Estos textos de Arendt como el de su esposo, evidencian el respeto y la admiración que tenían a Camus. Cabe recordar también que, tanto Camus como Arendt eran de la misma generación, aunque provenían de universos diferentes. Los dos tuvieron una etapa en la que estudiaron a San Agustín de Hipona. Además, a partir de 1930 los dos adquieren compromisos políticos y denuncian la emergencia de regímenes autoritarios. Sin embargo, Arendt siempre identificó a Camus de lado de Sartre, con la diferencia de que este último era un intelectual comprometido con una nueva filosofía positivista, por un nuevo humanismo, mientras que "Camus era menos fuerte intelectualmente que Sartre, pero más importante, más serio y más honesto" (Baudoui, 
2017, p. 4).

Tanto Arendt como Camus, tenían en común la denuncia del colonialismo, del imperialismo y de los totalitarismos, la lucha por la justicia social y la defensa de la dignidad humana. Además, afirmaban que el nazismo y el comunismo forjaron la matriz de los totalitarismos del siglo XX. Arendt abogó por la libertad y la rebelión, mientras que Camus era favorable a la resistencia y la revuelta. Para Arendt lo absurdo fue la muerte de millones de personas en los campos de concentración, fue el castigo a los inocentes; mientras que para Camus lo absurdo era parte inherente a la condición humana, debido a que "el hombre se encuentra sin cesar en la obligación de oponerse a las felicidades perecibles del cuerpo y a las intemperancias del alma" (Weyembergh, 1998, p. 56).

Como se analizaba anteriormente, la palabra existencialismo es prestada a la filosofía alemana moderna luego de la primera guerra mundial y que influenció a la filosofía francesa durante diez años. Bien es cierto que el existencialismo surgió tanto en Francia como en Alemania en el mismo periodo, en un contexto cultural muy semejante e idéntico (Arendt, 2002). Los existencialistas franceses, aunque diferentes entre ellos, comparten temas mayores de rebelión: primeramente, el rechazo a lo que ellos llaman l'esprit de sérieux ${ }^{4}, \mathrm{y}$, en segundo lugar, el rechazo obstinado de aceptar el mundo tal cual es, como el medio natural y predestinado del hombre (Sartre, 1943).

En primer lugar, l'esprit de sérieux puede ser asimilado a la respetabilidad, se trata de la persona que se presenta como dirigente, presidente, o como miembro de una facultad, es decir cuando la persona asume una actitud mitad natural y mitad social. Además, se identifica con una función arbitraria. Esta actitud corresponde a aquellos que, piensan que los valores morales se ubican antes de la existencia.

Al hablar de l'esprit de sérieux, se hace referencia a la negación absoluta de la libertad, debido a que el hombre se presta a la inevitable transformación que vivencia todo ser humano cuando se integra a la sociedad. En la teoría de Hannah Arendt (2002), significa volverse un ser social a plenitud dejando de lado el compromiso político. L'esprit de sérieux significa mala $f e$, es la vana dignidad que se manifiesta en la identificación respecto a su función. La mala fe es negar la constitución del ser, se trata de la conciencia irresponsable, se transforma en objeto y elimina la espontaneidad de la conciencia, niega el ser-para-sí (González, 2019).

Según Hannah Arendt, el sujeto de l'homme sérieux fue abordado por primera vez por Sartre en La Nausée (1938), en una formidable galería de escenas de ciudadanos respetables, les salauds. Luego aparece como tema central en la novela $L$ 'Étranger de Camus. Donde cuenta que el héroe del libro era extranjero, es un hombre ordinario que no acepta simplemente someterse al l'esprit de sérieux de la sociedad y que no acepta conformarse a las obligaciones de las funciones que se le atribuyen. Es un extranjero que nadie entiende, y paga con su vida. No acepta participar en el juego, se encuentra aislado de sus congénitos por una total incomprensión, pero se encuentra también aislado de él mismo, al punto de perder su facultad de expresión. En este sentido Arendt, recurre a Kant para argumentar sobre la necesidad de saber compartir la palabra en el espacio público, éste debe ser plural, y, al mismo tiempo, acoge las diferentes participantes de una comunidad determinada.

Luego, la expresión Huis Clos de Sartre, es una de las más bellas obras de teatro, donde trata sobre la relación con el otro (intersubjetividad). La acción se desarrolla en el infierno, un infierno muy semejante al mundo real. Tres personajes se encuentran en ese microcosmos. A primera vista sin unión entre ellos, resulta que sus historias están íntimamente unidas, los unos alienando a los otros, lo que lleva a la famosa conclusión de uno de los personajes: el infierno son los otros (1943). Aquí, los otros son aquellos 
que están fascinados por la propaganda y el poder seductor del totalitarismo. Son aquellos que se encuentran aislados del espacio público, silenciados, y que han perdido su capacidad de actuar.

Como la novela de Camus, la obra de teatro de Sartre niega que pueda existir verdaderamente una unión verdadera y profunda entre los hombres, una relación directa, inocente, libre de toda apariencia engañadora. El amor en la filosofía de Sartre es el deseo de ser amado, la necesidad de una confirmación suprema de su propia existencia. Para Camus el amor es una tentativa mal dirigida y desesperada de romper el aislamiento del individuo. Además, en la obra de Sartre, "el amor es conflicto", el hombre busca hacerse dueño de la libertad de la otra persona, busca hacerse dueño, que la libertad sea suya (Silva, 2018).

Según Arendt, para escapar de los falsos semblantes y l'esprit de sérieux, hay que ser lo que uno es realmente. Kafka, en el último capítulo de L'Amérique (1988), propone una nueva posibilidad de vida auténtica. Cada uno es invitado a elegir una función y actuar según lo que a él le gustaría ser. El papel elegido es la solución del conflicto entre funcionarios y el ser, entre ambición y realidad. Actuando según lo que uno es, se vuelve el ser humano que preserva su libertad de falsos semblantes de su función. Además, solamente actuando en lo que el hombre es, puede afirmar que él, no es nunca igual a sí mismo. El hombre es su vida y sus acciones, las cuáles nunca están terminadas antes del instante de su muerte, pertenecen a su existencia. La sociedad moderna despojó a cada persona de lo que era auténticamente; con la llegada del totalitarismo, los ciudadanos perdieron su coraje y valentía, permanecieron en el mundo de las tinieblas, de la pérdida de su libertad, del saber actuar de manera concertada con los demás.

El segundo elemento propio del existencialismo francés coloca el acento en el hecho de que el hombre no está amarrado en el mundo, se trata del sujeto de Mythe de Sisyphe: Essai sur l'absurde de Camus, y de La Nausée de Sartre. Para Camus, el hombre es esencialmente extranjero, ya que el mundo y el hombre no son hechos el uno para el otro; el hecho de que existan juntos hace de la condición humana un absurdo. El hombre es la única cosa (chose) en el mundo que no tiene su sitio, porque él no existe simplemente como un hombre entre los hombres. El hombre se encuentra prácticamente solo en su rebeldía y en su perspicacia; es decir, que su razonamiento le vuelve ridículo debido a que el don de la razón le ha sido acordado en un mundo en donde todo está dado y nada está explicado. En este sentido, según Arendt, los regímenes totalitaristas prohibían toda espontaneidad, todo estaba fríamente planificado y calculado, incluso los slogans estaban preparados, no era necesario pensar ni innovar (1995).

En el estudio de Arendt (2002), la versión propia de Sartre acerca de lo absurdo, de la existencia y lo contingente, se encuentra perfectamente ilustrado en La Nausée que fue publicado en el último número de Partisan Review con el título The Root of the Chestnut Tree (1949). Todo lo que existe tanto en cuanto se pueda juzgar no tiene la mínima razón de ser. Es simplemente superfluo, de trop. El hecho de que yo sea incapaz de imaginar un mundo en el cual no habría demasiadas cosas sino la nada, da a conocer la impotencia y la desesperanza del hombre eternamente arrojado en su existencia. Es aquí donde se separan Sartre y Camus. Éste, aparentemente, continúa el desarrollo de una filosofía del absurdo, mientras que, Sartre, se compromete en una nueva filosofía positiva, un nuevo humanismo.

Camus, probablemente, rechazó ser calificado existencialista debido a que el absurdo no reside en el hombre o en el mundo, sino que se manifiesta solamente cuando ellos son rechazados juntos. La existencia del hombre no se desarrolla en el hombre, es un absurdo, debe ser vivido en el absurdo. El absurdo de la existencia consiste en 
rebelarse sin descanso contra las múltiples manifestaciones y sus consolaciones. Esta revuelta es el precio de la vida, queda solamente una cosa aceptable, es la suerte misma, es un hasard roi, quien aparentemente se ha divertido en reunir el hombre y el mundo.

Para Sartre, el absurdo no se sostiene solamente en la esencia de las cosas, sino de aquellas del hombre. Todo lo que existe es absurdo, del hecho mismo de su existencia. El hombre es un creador y comprende entonces que, no depende de nadie fuera de sí mismo y que puede ser libre y maestro de su propio destino. Este puede ser el mensaje esencial de la obra de Sartre.

Camus y Sartre, tienen un punto positivo en común: el no mantener ninguna nostalgia por días felices pasados así hayan sido mejores que los nuestros en la actualidad. Ellos no creen en la magia de aquello que ha pasado, ellos no hacen ningún compromiso. Conviene en este contexto, profundizar el existencialismo de Sartre, y, como se decía más arriba, difiere de los otros promotores del existencialismo.

\section{El EXISTENCIALISMO DE SARTRE}

Según Sartre, el existencialismo es una doctrina que hace posible la vida humana, que toda verdad y toda acción implican un medio y una subjetividad humana; se trata de una doctrina la menos escandalosa y la más austera, dirigida a técnicos y a filósofos. Según Sartre, hay un existencialismo cristiano católico (Jaspers y Gabriel Marcel) y otro que es ateo (Heidegger); y, además, el existencialismo francés, en el cual se encuentra Sartre. Lo que une a todos estos tipos de existencialismo es que "la existencia precede a la esencia" (Sartre, 1946, p. 37); es decir, que hay que partir de la subjetividad. Al contrario, Heidegger (1986) afirma haber encontrado un ser donde existencia y esencia son perfectamente idénticos: el hombre. Su esencia es su existencia. La substancia del hombre no es su espíritu... sino la existencia. Se trata, en efecto, de hacer del hombre directamente maittre de l'être, de esta manera el hombre es colocado en el sitio donde la ontología tradicional ubicaba a Dios. Jaspers afirma que la existencia nunca puede estar en la esencia, aislada, ella se encuentra en la comunicación y en el saber de otras existencias, se encuentra entre los hombres, en el mundo dado a todos (1919).

El existencialismo declara que el hombre es angustia, pero que no conduce al quietismo sino a la inacción, más bien se trata de las angustias simples de aquellos que tienen responsabilidades, las cuales no impiden que se actúe, al contrario, es la condición misma de la acción que tiene múltiples posibilidades. El destino del hombre, y el hecho de vivir es el acto, y para esto se necesita una moral de acción y de compromiso. La angustia, según Heidegger, es aquella que se sitúa frente a la muerte, se manifiesta el ne-pas-être-chez-soi en el mundo. Solamente con la muerte el ser sale del mundo, el hombre tiene la certeza de no ser solo uno mismo. Este yo es el quien del ser ahí. Un yo, considerado en el aislamiento absoluto no tiene sentido (Arendt, 2002) La muerte es el fin del ser ahí, es el aislamiento absoluto.

Los valores del existencialismo, honestidad, verdad, paz, existen en el "cielo de lo inteligible", y sí Dios no existe, los valores como la honestidad, el progreso y el humanismo continuarán. Para llegar a la verdad se necesita pasar por el otro. El otro es indispensable para mi existencia, de manera que el descubrimiento de mi intimidad descubre también la del otro (Sartre, 1946). Para el existencialismo, lo que cuenta es la realidad. Frecuentemente se presenta como un todo homogéneo, de ahí que sea mejor hablar de existencialismos: Sartre es diferente a Kierkegaard, a Jaspers y a Pascal. Una de las grandes diferencias entre estos autores es el asunto de Dios. 
En el estudio de Sartre, Dios es siempre considerado como un artesano superior que crea. Sartre se confiesa como un existencialista ateo, y afirma que "si Dios no existe, hay al menos un ser donde la existencia precede a la esencia" (p. 39), un ser que existe antes de poder ser definido por ningún concepto, este ser es el hombre, y es lo que él hace, es responsable de lo que es. Es responsable total de su existencia. Nada cambiará si Dios no existe.

Para el existencialismo es muy peligroso afirmar que Dios no existe, porque también desaparecería todo posibilidad de encontrar valores en un cielo inteligible. Según Sartre, el existencialismo parte de la afirmación: "Si Dios no existe, todo estaría permitido" (p. 42). En este sentido, el hombre no depende de Dios, él se define por sus elecciones y actos; es decir, todos nacen hombres, pero son los actos los que hacen del ser humano malo o no. Sin embargo, felizmente, nuestros actos pueden cambiar nuestra esencia, es lo que nos distingue de los objetos.

El hombre es poseedor de una naturaleza humana que es común a todos los hombres; es decir, que cada hombre es un ejemplo particular del concepto universal, el hombre existe primero, es lo que proyecta hacia el futuro. Cada hombre se elige, y, eligiéndose, elige también a todos los hombres, y, lógicamente, que se elige el bien. Esto lleva a la idea de que "yo soy responsable de mí mismo y de los otros" (p. 40) El existencialismo propone la posibilidad de crear una comunidad humana.

Si la existencia precede a la esencia, esto significa que no hay determinismo, el hombre es libre, más aún: "l’homme est condamné à être libre" (Sartre, p. 1946: 41), el hombre está condenado a ser libre, condenado debido a que él no se ha creado a sí mismo, y una vez arrojado (jeté) al mundo, él es responsable de todo lo que él hace, se encuentra condenado a cada instante a inventar el hombre, debido a que "el hombre es el futuro del hombre" (p.42), hay un futuro a hacer y a construir, un futuro virgen, no hay decisiones a priori. Al ser hombre libre, éste asume toda la responsabilidad de sus actos individuales y colectivos. No hay libertad sin responsabilidad.

El hombre tiene que fiarse de sus instintos, de sus sentimientos, los cuales se construyen por los actos que se realizan, no es la moral de conceptos que me van a permitir actuar. Aquí Sartre valora lo que Hannah Arendt excluye de su teoría política. Más bien Sartre se inclina por la posición de Ferdinand de Tönnies, quien considera que los integrantes de una comunidad se unen por la amistad, los sentimientos y afectos, que incluso puede ser el nexo espiritual que puede unir íntimamente a los individuos de una comunidad determinada (1946) Según Sartre, se trata, entonces, de ser libre para elegir y para inventar. El invento y la creación se manifiestan justamente en el arte y la moral, no se puede decidir a a priori lo que hay que hacer. El hombre se hace eligiendo la moral, cuando la mala fe es evidentemente una mentira (Sartre, 1946), mientras que los actos buenos de los hombres de buena fe buscan la libertad de los otros, y esta libertad de los otros depende de la nuestra, un compromiso. Los inventos se hacen a nombre de la libertad. La interpretación de Sartre difiere de la de Hannah Arendt en el sentido de que la libertad para ella es eminentemente política; los ciudadanos son libres para participar en el espacio público en el marco de unas leyes establecidas en una Constitución, cuyo paradigma se encuentra en la antigüedad, en Grecia y Roma, pero, sobre todo, en la Revolución norteamericana (2002).

El hombre debe comprometerse y no mantenerse quieto; no se necesita esperar para comenzar. La actitud del quietismo es propia de las personas que dicen que los otros pueden hacer lo que no puedo hacer, de ahí que, para Sartre, la realidad se encuentra en la acción, ella va más lejos (p. 47). Sartre siempre dio buen ejemplo de ser un hombre de acción política participando mediante palabras y acciones muy concretas y definidas. 
Hay una condición de universalidad humana, es por eso que se habla de condición humana más que de naturaleza. El ser humano necesita estar en el mundo, de estar en el trabajo, en la mitad de los otros y de ser mortal (Sartre,1946). Todo proyecto individual del hombre tiene repercusiones universales; hay universalidad en todo proyecto. Yo construyo lo universal eligiéndome y, construyo comprendiéndome, el proyecto de todo hombre, de cualquier época que sea. Ser libre y ser como proyecto, como existencia que elige su esencia. El ser en el mundo no es aquel que se encuentra entregado a la muerte, no se viene al mundo para morir, sino para vivir. Hay que esforzarse por un nuevo humanismo.

Para Sartre, el humanismo tiene dos sentidos muy diferentes. En cuanto al primer sentido, por humanismo se entiende una teoría que toma al hombre como fin y como valor superior: este humanismo es absurdo. El segundo sentido de humanismo se manifiesta cuando el hombre se encuentra constantemente fuera de sí mismo, es proyectándose y perdiéndose fuera de sí lo que hace existir al hombre y, de otra parte, es siguiendo sus objetivos trascendentales como él puede existir. No hay otro universo que el universo humano, el universo de la subjetividad humana. Esta unión de trascendencia, como constitutiva del hombre y de la subjetividad, en el sentido de que el hombre no se encuentra cerrado en sí mismo, sino presente siempre en el universo humano, es el humanismo existencialista, no hay otro legislador que el mismo; debe buscar fuera de sí un objetivo que es la liberación. Se trata también de llevar a cabo un ateísmo coherente, no se trata de hundir al hombre en la desesperación, no se trata de demostrar que Dios no existe, sino que, así Dios exista, no cambiará en nada. El hombre debe encontrarse a sí mismo y persuadirse de que nada puede salvarle de él mismo. En este sentido, el existencialismo es un optimismo porque es una doctrina de acción (1946).

\section{Conlcusión}

Jean Paul Sartre representa una resistencia intelectual, al igual que Hannah Arendt, frente a una Europa y una Francia devastadas. El auge del nacionalsocialismo había coartado las libertades individuales y colectivas; la complicidad y el silencio de muchas instituciones, incluidas las confesantes, habían reducido a la población al ámbito de lo privado. Justamente, es aquí donde Sartre, un académico relevante, se compromete políticamente, mostrando además que el filósofo no puede ser neutral y alejado de los problemas ciudadanos. Sartre tuvo la sabiduría y la valentía para saber combinar academia y militancia acompañando a los grupos sociales de la época.

Sartre es un pensador critico respecto a la sociedad de su tiempo, época en la que l'esprit de sérieux de la gente hacía que los individuos no se mostraran tal cual eran, y, además, no estaban a favor de la libertad; se trataba de gente de mala fe, con conciencia irresponsable no favorable a la espontaneidad y enemigos de la libre expresión de los ciudadanos. Esta actitud de la gente, provoca desunión entre los hombres donde el uno se hace dueño de la libertad del otro. Sartre critica esa sociedad de apariencias y de falta de una vida autentica, de un nuevo humanismo en el que cada ciudadano se sienta responsable de su propio destino.

El existencialismo promueve la acción de los ciudadanos que, mediante la práctica de valores emergentes, como la honestidad y la verdad, les permite llegar a la verdad con los otros, en comunidad. El hombre no está predeterminado a nada, al contrario, es promotor de su propia historia, con actitudes responsables consigo mismo y con los demás puede ser libre; él es el único responsable de lo que hace. Finalmente, 
el hombre existencialista debe ser capaz de crear, de inventar y de salir adelante. El existencialismo, lejos de ser una filosofía pesimista, es una invitación al optimismo, a la esperanza, donde el hombre es el constructor de su destino, el único responsable de lo que le suceda.

136 ARENDT, H. y Jaspers, K. (2006), La philosophie n'est pas tout à fait innocente, Paris : Payot.

ARENDT, H. (2003), Condition de l'homme moderne, Paris : Seuil.

ARENDT, H. (2002), Qu'est-ce que la philosophie de l'existence? suivi de L'existentialisme francais, Paris : Rivages poche Petite bibliothèque.

ARENDT, H. (1996), Heinrich Blücher, Briefwechsel, 1936-1968, Paris: Calmann-Lpevy.

ARENDT, H. (1995), Qu'est ce que la politique, Paris ; Seuil.

Baudoui, R. (2017), Hannah Arendt et Albert Camus, Université de Genève, vol. 9, pp.

13-27

FANON, F. (1963), Los condenados de la tierra, México: FCE.

FERRY, L. (2006), Kant, Une lecture des trois Critiques, Paris : Bernard Grasset.

GONZÁLEZ, S. (2019), Existencia, libertad y mala fe: revisión a la ontología fenomenológica y al psicoanálisis existencial de Jean-Paul Sartre, Revista de Filosofía, Vol. 3, № 1, pp. 8295.

HEIDEGGER, M. (1986), Etre et temps, Paris : Gallimard.

JASPERS, k. (1919), Psychologie des conceptions du monde, Paris : Vrin.

KAFKA, F. (1988), L'Amérique (Trad. Vialatte, A.), Paris : Gallimard.

SARTRE, J.P. (1946), L'existencialisme est un humanisme, Paris : Nagel.

SARTRE, J.P. (1943), L'être et le Néant, Paris : Gallimard.

SARTRE, J.P. (1938), La Nausée, Paris : Gallimard.

SILVA, G. (2018), Jean Paul Sartre: breves reflexiones sobre su pensamiento anticolonial, En: Encuentros. Revista de Ciencias Humanas, Teoría Social y Pensamiento Crítico, $\mathrm{N}^{\circ} 7$, pp. $77-90$.

TÖNNIES, F. (1946), Communauté et sociéte. Paris : Presses Universitaires de France.

WEYEMBERGH, M. (1998), Albert Camus ou la mémoire des origines, Paris-Bruxelles : De Boeck. 